\title{
A CONSTRUÇÃO DA CATEGORIA NA PERSPECTIVA DA ANÁLISE DIALÉTICA - uma aula de Octávio Ianni
}

\section{Mariluce Bittar ${ }^{1}$}

Iniciávamos a segunda metade dos anos 1980 e a Pontifícia Universidade Católica de São Paulo expressava intensamente o movimento da sociedade brasileira pós-ditadura militar. Nos Programas de Pós-Graduação, nos cursos de Graduação, nos corredores, nas pichações... tudo ainda "respirava" e transpirava a luta que aquela Universidade e seus protagonistas travaram contra os anos de repressão comandados pelos "generaispresidentes".

A história registra o quanto e como a PUCSP abrigou aqueles intelectuais que, banidos de suas universidades, cassados ou expulsos do País, voltaram com o propósito de colaborarem na resistência à ditadura desde o final da década de 1970, processo que culminou no movimento pelas Diretas-Já e com a sua derrota no Congresso Nacional, em 1984, frustrando as forças de esquerda e o movimento democrático em geral. Foi então, que o Colégio Eleitoral elegeu no ano seguinte, pela via indireta, Tancredo Neves presidente da República. A efervescência política era forte, o Partido dos Trabalhadores (PT), ainda com poucos anos de vida, mas em ascensão, havia deliberado que seus deputados votassem contra. A polêmica e as discussões eram acirradas. Em todos os fóruns políticos, sindicais e acadêmicos, o assunto estava em pauta. Na PUC, altamente mobilizada, o fim da ditadura daquela forma, conservando fortes traços de continuidade do regime, era assunto cotidiano e nesse ambiente politicamente estimulante frequentemente encontrávamos, nos corredores, os professores Florestan Fernandes, Paulo Freire, Maurício Tragtemberg, Octávio Ianni, entre outros.

Eu iniciara o Curso de Mestrado, no Programa de Pós-Graduação em Serviço Social, em 1983, ano em que se comemoravam os 100 anos da morte de Karl Marx (18181883). Movida pela minha recente militância no movimento estudantil, no final dos anos 1970, quando cursava Serviço Social nas Faculdades Unidas Católicas de Mato Grosso (FUCMT), queria matricular-me nos cursos de todos esses professores, na ânsia de não perder nada de importante nos anos em que tive o privilégio de ser estudante naquela Universidade que se transformou em símbolo da luta contra a ditadura.

Juntamente com minha amiga, Sandra Maria Pereira Mello, que também cursava Mestrado em Serviço Social, resolvi assistir aos cursos de Florestan Fernandes e Octávio Ianni, mas suas disciplinas eram disputadíssimas e a prioridade era para os pós-graduandos do Programa de Ciências Sociais, ao qual eles estavam vinculados. Contentamo-nos com a condição de "alunas ouvintes", pois não poderíamos perder a oportunidade de aprender com os grandes expoentes da sociologia no Brasil. Talvez, naquela época, não tivéssemos tanta consciência do quanto aqueles cursos e seus conteúdos, especialmente a leitura dos autores clássicos, significariam em nossa formação intelectual. Mas tínhamos certeza de que não poderíamos "passar pela PUC" sem freqüentar aquelas disciplinas, cujas discussões guardavam relação direta com as reflexões que vínhamos fazendo nas aulas do Programa de Pós-Graduação em Serviço Social, da mesma Universidade, notadamente nos cursos dos professores Evaldo Amaro Vieira e Nobuco Kameyama. No meu caso, além de assistir as aulas de Florestan Fernandes e Octávio Ianni, matriculei-me nas disciplinas de pesquisa em ciências humanas e sociais, ministradas pelo professor Luís Eduardo Wanderley, que era vinculado ao Programa de Ciências Sociais e, logo depois, foi Reitor da PUCSP. Suas aulas também foram um diferencial em minha formação como 
pesquisadora, pois descortinaram outras formas de realizar a pesquisa nas ciências humanas e sociais, na perspectiva do método dialético e das abordagens qualitativas.

Mas não era somente o interesse em assistir as aulas de alguns dos grandes pensadores da sociologia no Brasil que nos levava a procurar o Curso de Sociologia do professor Octávio Ianni; era também a admiração por intelectuais de "primeira grandeza" do pensamento sociológico brasileiro, cuja militância contra a repressão e a censura impostas pela ditadura militar fizeram de suas trajetórias de vida, exemplos para as futuras gerações de pesquisadores e cientistas sociais brasileiros.

Octávio Ianni foi aluno de Florestan Fernandes, quando de sua formação na Universidade de São Paulo e, junto com o mestre "[...] colaborou ativamente para fazer da cátedra de Sociologia I um marco das ciências sociais da antiga Faculdade de Filosofia, Ciências e Letras da rua Maria Antônia, em São Paulo. Nascido em Itu, em 1926, pertenceu a uma geração de professores da USP decisiva na consolidação dos estudos sociológicos voltados para o conhecimento do Brasil" (http://www.conteudoescola....). Ele fez parte da "Escola de São Paulo", "[...] como ficou conhecido o grupo de sociólogos surgido no início dos anos 1950, na USP, em torno do nome de Florestan Fernandes [...]" que reunia também Fernando Henrique Cardoso, futuro presidente da República. (http://www.rodaviva.fapesp ...).

Em 1969, no entanto, como uma das conseqüências do Ato Institucional número 5, editado em 1968, pelos militares, o qual restringia as liberdades civis e cassava os direitos políticos daqueles que se opunham ao regime, Octávio Ianni foi aposentado compulsoriamente, sendo impedido de lecionar naquela que representava uma referência nacional na formação intelectual brasileira, a Universidade de São Paulo. Mas para sorte das futuras gerações de cientistas sociais, foi recebido na Pontifícia Universidade Católica de São Paulo, juntamente com seu mestre, Florestan Fernandes, e muitos outros intelectuais, que puderam continuar exercendo a crítica, a liberdade de pensamento e a produção do conhecimento sobre os problemas nacionais. Mas, diferentemente de seu mestre, que viria a atuar como parlamentar, eleito pelo Partido dos Trabalhadores, Ianni viveu toda a sua vida na sala de aula. A história registra que até poucos dias antes de sua morte, em 2004, ele ainda ministrava aulas na Universidade Estadual de Campinas (UNICAMP). Para Samira Marzochi (2004), o professor Ianni “[...] surpreendeu mais uma vez. Embora convivesse com um grave problema de saúde, não se deixava abater, movido por uma grande paixão pelo trabalho intelectual e acadêmico”. Além disso, nos últimos dez anos de vida, descobriu o seu interesse final: a globalização e seus efeitos sobre os países do Terceiro Mundo, tema sobre o qual publicou artigos e o livro A era do globalismo. Quando de sua morte, a Revista Pesquisa FAPESP, publicou uma matéria registrando que paixão e rigor marcaram, em doses iguais, a trajetória do grande intelectual, que começara com estudos sobre a questão racial em Florianópolis, uma dissertação que, em 1956, lhe conferiu o título de Mestre, na Faculdade de Filosofia Ciências e Letras da USP.

Faço minhas as palavras de Samira Marzochi, que também foi sua aluna (na UNICAMP), anos depois de mim, ao afirmar que ele era:

[...] sensível, sobretudo, às questões relacionadas à desigualdade social, à dominação do capital, aos abusos de poder, mas não se deixava fechar numa visão restrita da realidade, muito menos parar no tempo. Assimilava com precisão e rigor tudo o que acontecia de novo, quando apontava problemas, limites, ou quando se empolgava, acreditando que a novidade deveria conter um germe de transformação. Sua visão era predominantemente marxista. Mas o Marx de Octavio Ianni era o próprio 
Ianni: era o jovem, o velho o filósofo, o historiador, o erudito e, principalmente, o idealista. Fazia do trabalho intelectual algo de importância revolucionária. Genuinamente revolucionária. Sempre de pé, falando pausadamente, mas de modo enfático e olhando para cada aluno, lançava frases desconcertantes, inesperadas, como se dialogasse com o nosso pensamento e ao mesmo tempo com o mundo. (Marzochi, 2004, grifos da autora)

É exatamente essa a sensação que todos tínhamos ao assistir as suas aulas. Não ousávamos sair da sala no meio de sua preleção; muitos de nós levávamos gravadores, para depois ouvir suas análises e interpretações sobre a realidade brasileira, sobre como poderíamos compreender "nossos objetos de pesquisa à luz do método histórico-dialético", como ele brilhantemente e insistentemente nos ensinava. Era organizado com suas aulas, tinha sempre um tema a ser desenvolvido e as primeiras duas horas ou até mais, eram destinadas à sua explanação, momento em que se poderia ouvir até a respiração dos alunos, tal era o silêncio que reinava na sala e o desejo de não interromper o seu raciocínio, sempre tão claro e didático.

Um professor como poucos que, tendo vivido e sofrido os efeitos da ditadura militar, nem por isso deixava de nos incitar à mudança, à busca da transformação. Como afirmou Samira Marzochi (2004): "Entrar e sair da aula do professor Ianni (...) era passar por um processo de transformação". Quem, como eu, teve o privilégio de ter sido sua aluna, jamais esquecerá seus ensinamentos e o seu exemplo de professor e de sociólogo, que fazia das aulas um fértil exercício de práxis: conseguia, como poucos, aliar o conhecimento teórico-epistemológico, fundamentado nos clássicos do pensamento sociológico contemporâneo, à análise dos problemas brasileiros, como se poderá constatar na aula sobre a "construção da categoria", a seguir publicada. Por essas e muitas outras razões e atributos Octávio Ianni foi, "[...] sem dúvida, um dos professores mais dedicados, um dos orientadores mais competentes e um dos sociólogos mais produtivos, sem que isso comprometesse a qualidade e a beleza de suas aulas." (Marzochi, 2004)

É essa "beleza", esse encantamento, que finalmente resolvi trazer a lume, por meio de uma aula (gravada com sua autorização) que transcrevi e utilizei todos esses anos em minhas disciplinas nos cursos de graduação, mas principalmente, na pós-graduação (Mestrado e Doutorado em Educação), dos quais sou professora. Meus alunos sempre me perguntavam por que eu não publicava aquela aula, pois seria de mais fácil acesso para muitos que seguiam os mesmos caminhos teórico-metodológicos. Mas eu não o fazia, porque sentia que era como se fosse mexer em algo intocável, de um momento que havia sido meu e de meus colegas, daquele longínquo ano de 1985. Como se aquele momento, quase mágico, que havíamos tido o privilégio de desfrutar com o professor Octavio Ianni, devesse ser guardado tão somente na memória de nossa formação intelectual e nos nossos corações.

Não obstante, com o passar dos anos, outros professores e amigos solicitavam-me cópia da aula. Percebi que não estava sendo coerente com o método, com a concepção de mundo e de sociedade que aprendi não apenas em suas aulas, mas nas de outros grandes intelectuais, entre eles o também inesquecível Florestan Fernandes, além da minha militância político-partidária. Aprendi e incorporei aqueles ensinamentos tanto em minha atividade intelectual, de produção acadêmica, como também em minha prática como professora universitária, tentando não decepcionar os "mestres". Por isso, mais de duas décadas após aqueles memoráveis encontros, entendi que ao publicar a última aula que assisti do professor Ianni, eu estaria socializando os conhecimentos adquiridos naqueles anos e, ao mesmo tempo, prestando-lhe uma justa homenagem. 
Em seu Programa de Disciplina, denominada simplesmente Sociologia, o professor Ianni registrava:

A disciplina Sociologia, para a pós-graduação, pode concentrar-se na discussão de uma teoria da sociedade, dentre as várias reconhecidas como fundamentais. Todo aluno de pós-graduação já possui uma formação básica, na qual se incluem as diferentes teorias da sociedade. Mas essa formação pode ser desenvolvida, desde que ele retome, em forma demorada, uma dessas teorias. (IANNI, 1985a, grifos meus)

Sua insistência para que os alunos estudassem as teorias clássicas por meio da leitura dos "textos originais", está presente em toda a aula sobre "A construção da categoria", ao afirmar que era necessário um trabalho obstinado, perseverante e contínuo do conhecimento do real. E, para tanto, não deveríamos nos contentar com a leitura dos comentaristas, pois:

[...] uma leitura do 'Capital' é sempre bom, uma leitura sistemática, mas tomar obras de Marx como '18 Brumário', como a 'Miséria da Filosofia' e, eventualmente, outras obras de outros autores e estudar, trabalhar com calma, com atenção, com anotações. Estudar a obra, a textura, a articulação, a maneira pela qual se constrói. Descobrir o segredo daquele pensamento. Nesse sentido é que eu acho que a leitura dos comentaristas deve ser sempre auxiliar. $O$ comentarista é bom para chamar a atenção sobre o problema que às vezes escapam da gente. Mas desde que a gente esteja lendo o principal. Contentar-se com comentaristas bons, eu acho que é pouco. É um modo aproximado do trabalho. Mas é importante estudar o texto original e, um tanto quanto possível, os textos principais. (IANNI, 1985b, grifos meus)

Continuando na exposição de como ele abordaria a análise da sociedade, assim está escrito em seu Programa de Disciplina:

O objetivo da disciplina aqui proposta é expor e discutir alguns temas centrais da teoria dialética da sociedade. Essa teoria aborda temas que não são habitualmente focalizados pelas teorias funcionalistas, tipológica, estrutural-funcionalista, estruturalista e outras. E aborda outros que são examinados também por essas teorias, mas de forma diversa. Estes são alguns dos temas que têm recebido tratamento especial, no âmbito da teoria dialética da sociedade: dialética das relações sociais, aparência e essência, existência e consciência, a historicidade do social, a noção de totalidade dialética, contradição, as formas sociais do trabalho, indivíduo e sociedade, fetichismo e cultura, arte e sociedade, o intelectual e a cultura, ciência e ideologia, histórico e lógico, a construção da categoria.

A teoria dialética da sociedade não está organizada em um corpo de princípios, conceitos ou regras claramente delimitados e amplamente aceitos; está pouco sistematizada. Além disso, acha-se dispersa na obra de vários e diferentes autores, desde Marx a Gramsci. São desiguais as contribuições dos diferentes autores. Inclusive há divergências básicas. Mas é inegável que eles contribuíram para a formulação de uma teoria da sociedade. Ocorre que a teoria dialética da sociedade apreende e explica o social de modo suficientemente original para merecer atenção. Acresce que é referência freqüente nas controvérsias entre as várias teorias da sociedade. Por esses motivos, é fundamental que o estudante 
desenvolva e aprofunde o conhecimento da teoria dialética da sociedade. (IANNI, 1985a, grifos meus)

Em seguida o Programa trazia os temas que seriam desenvolvidos para se compreender a teoria dialética da sociedade, cada um em uma semana, totalizando 14 encontros, com a seguinte explicação: "Naturalmente um ou outro tema pode ser mais ou menos desenvolvido, modificado, substituído. Inclusive pode haver acréscimos" (IANNI, 1985a). Os temas que estudamos naquele primeiro semestre de 1985, foram: 1) Dialética das relações sociais; 2) Aparência e essência; 3) Existência e consciência; 4) As formas sociais do trabalho; 5) A historicidade do social; 6) A noção de totalidade dialética; 7) Contradição; 8) Indivíduo e sociedade; 9) Fetichismo e cultura; 10) Arte e sociedade; 11) O intelectual e a cultura; 12) Ciência e ideologia; 13) Histórico e lógico; 14) A construção da categoria. (IANNI, 1985a)

Ao final da listagem dos temas, o professor Ianni ainda ressaltava em seu Programa: "Os temas referidos acima podem ser trabalhados e aprofundados, em larga medida, com base na análise de: Marx, O Capital”. (IANNI, 1985a)

Sua bibliografia, portanto, estava quase inteiramente fundamentada nas obras de Karl Marx: "O Capital" (três livros); "Elementos Fundamentales para la Critica de la Economia Política"; "Contribuição à Crítica da Economia Política" e "O Capital", Livro I, Capítulo VI (inédito). Em seguida vinham as obras de Karl Marx com Friedrich Engels: "A Ideologia Alemã" (Feuerbach); "Cartas Filosóficas e Outros Escritos", além de "Do Socialismo Utópico ao Socialismo Científico"; "Ludwig Feuerbach y el fin de la Filosofia Clássica Alemana", ambos de autoria apenas de Engels. As obras de Antonio Gramsci, como "Concepção Dialética da História"; "Maquiavel, a Política e o Estado Moderno" e "Os Intelectuais e a Organização da Cultura", também foram leituras obrigatórias na disciplina. De Lênin ele selecionou "Cahiers Philosophiques"; de Lukacs, "História e Consciência de Classe" e de István Mészáros, "Marx's Theory of Alienation" (IANNI, 1985a). Mais alguns autores, além desses, formavam a bibliografia de 23 (vinte e três) obras clássicas que deveríamos ler durante o semestre, com sua recomendação de que:

Aqui surge uma sugestão mais do que evidente. Não se trata de ler, sejam os clássicos do marxismo, sejam comentaristas de modo indiscriminado. Uma boa formação teórica não depende de uma leitura exaustiva da obra de todos esses autores. Ela depende de um trabalho denso na medida do possível, trabalho sistemático, sobre algumas das obras. Eu acho que o que está apresentado nesse curso e que tem a ver com experiências que seguramente vocês já têm, e certamente alguns já trabalharam "O Capital", já trabalharam essas idéias, tem de aprofundar a elaboração de uma visão teórica da realidade. Essa visão teórica, ela vai ser útil não só para fazer um trabalho escolar, ou para fazer uma pesquisa. Mas ela vai ser útil como uma maneira de ver o mundo com outras cores, o que não significa que cada um vai assumir essa posição. (IANNI, 1985, grifos meus)

A aula, a seguir publicada, como escrito anteriormente, foi a última do semestre. Cada vez que leio esse texto, junto com meus alunos da Pós-graduação em Educação, em especial nas disciplinas de Pesquisa em Educação e em Seminário de Tese, fico encantada com o brilhantismo de sua explicação sobre a "teoria dialética da sociedade", sobre a necessidade de entendermos "que a realidade é complexa, é heterogênea, é contraditória [..]" e, portanto, o trabalho do pesquisador não consiste "apenas em conhecer", em "repetir os pensamentos que são estudados, as contribuições da dialética que foram discutidas. Se trata de aperfeiçoar esse conhecimento e fazer o possivel para repensar os 
problemas, tendo em conta a possibilidade de desenvolver alguma reflexão nova" (IANNI, 1985b)

Anos mais tarde, em 1998, assisti a uma conferência do professor Octávio Ianni sobre a Obra de Florestan Fernandes. O evento ocorreu no Auditório Florestan Fernandes, na Universidade Federal de São Carlos (UFSCar), onde eu terminava o Doutorado em Educação e que estava entregando ao público a Biblioteca Florestan Fernandes, com todo o acervo particular que um dos maiores sociólogos brasileiros havia deixado para uma universidade pública. Ianni analisou duas fases nas obras de seu exprofessor: a fase intelectual, dos escritos sociológicos e a fase de sua militância políticopartidária. Que conferência! Sem data show, sem papéis, sem anotações, sem qualquer recurso que não fossem sua própria $\mathrm{voz}$ e inteligência, fato que propiciou a todos deleitarem-se plenamente com o seu profundo conhecimento sobre a obra daquele que também o inspirou.

Após a conferência fui conversar com ele, me apresentei, dizendo que tinha sido sua aluna em 1985, mas, claro, ele não se lembrava. No entanto, sua alegria quando contei de sua influência em minha formação, em minha trajetória acadêmica, foi tão grande que me senti recompensada! Foi a última vez que o vi, mas jamais me esquecerei de sua fisionomia risonha por reencontrar uma ex-aluna da PUC de São Paulo, daquela fase tão marcante do final da ditadura militar, política e intelectualmente significativas para ele, e que, para mim, jamais será esquecida.

\section{Referências}

IANNI, Octavio. Sociologia. Plano de Disciplina. Programa de Estudos Pós-Graduados em Ciências Sociais. São Paulo: PUC-SP, 1985a. (arquivo particular).

IANNI, Octavio. A construção da categoria. Aula ministrada no Programa de Estudos Pós-Graduados em Ciências Sociais. São Paulo: PUC-SP, 1985b. (a seguir transcrita)

http://www.conteudoescola.com.br/site/content/view/82/39 [Acesso em 20 de fevereiro de 2011]

http://www.rodaviva.fapesp.br/materia_busca/45/Ianni/entrevistados/octavio_ianni_20 [Acesso em 20 de fevereiro de 2011]

MARZOCHI, Samira Feldman. Homenagem ao professor Octavio Ianni.(2004). Disponível em: http://www.adur-rj.org.br/5com/pop-up/homenagem_O_Ianni.htm [Acesso em 20 de fevereiro de 2011].

Notas:

\footnotetext{
${ }^{1}$ Doutora em Educação (UFSCar); Professora do Programa de Pós-graduação em Educação da Universidade Católica Dom Bosco (UCDB); Coordenadora do Grupo de Estudos e Pesquisas Políticas de Educação Superior (GEPPES); Editora da Série-Estudos. Bolsista de Produtividade em Pesquisa do CNPq. E-mail: bittar@ucdb.br. Agradeço a colaboração de minhas alunas de Iniciação Científica da UCDB que digitaram a aula "A Construção da Categoria”: Andressa dos Santos de Souza; Lucélia Aparecida Gomes Fernandes e Mariele Nogueira de Oliveira.
}

Recebido em: $\quad$ 28/02/11

Aprovado em: $\quad 31 / 05 / 11$ 